\title{
Clinical significance in non-cystic fibrosis bronchiectasis followed in a real practice ${ }^{1}$
}

\author{
Relevância clínica em não fibrose cística \\ bronquiectasia seguida em uma prática real
}

\section{Newton Santos de Faria Júnior ${ }^{[a]}$, Amilcar Marcelo Bigatão ${ }^{[\mathrm{b}]}$, Sérgio Ricardo Santos ${ }^{[\mathrm{c}]}$, Fernando Sérgio Studart Leitão Filho ${ }^{[\mathrm{d}]}$, José Roberto Jardim ${ }^{[\mathrm{e}]}$, Luis Vicente Franco Oliveira ${ }^{[\mathrm{f}]}$}

[a] Physiotherapist, MSc, Master's Program in Rehabilitation Sciences, Universidade Nove de Julho, São Paulo, SP - Brazil, e-mail: nsdfj@yahoo.com.br

[b] Pulmonologist, MD, Center for Pulmonary Rehabilitation, Pulmonology Department, Universidade Federal de São Paulo, São Paulo, SP - Brazil, e-mail: abigatao@yahoo.com.br

[c] Pulmonologist, PhD, Center for Pulmonary Rehabilitation, Pulmonology Department, Universidade Federal de São Paulo, São Paulo, SP - Brazil, e-mail: sergioricardosantos@uol.com.br

[d] Pulmonologist, PhD, Professor, Medicine School, University of Fortaleza, Fortaleza, CE - Brazil, e-mail: fernandosturdart@uol.com.br

[e] Pulmonologist, PhD, Professor, Pulmonology Department, Universidade Federal de São Paulo, São Paulo, SP - Brazil, e-mail: jardimpneumo@gmail.com

[f] Physiotherapist, PhD, Professor and Researcher, Master's and Doctoral Programs in Rehabilitation Sciences, Universidade Nove de Julho, São Paulo, SP - Brazil, e-mail: oliveira.lvf@uninove.br

\begin{abstract}
Introduction: Bronchiectasis is a chronic disorder characterized by permanent dilation of the bronchi and bronchioles accompanied by inflammatory changes in the walls of these structures and adjacent lung parenchyma. Objective: The aim of the present study was to perform a clinical and functional characterization of adult patients with non-cystic fibrosis bronchiectasis. Methods: A clinical, descriptive, retrospective, case-series study was carried out involving 232 patients with non-cystic fibrosis bronchiectasis treated at a lung

1 Authors' contributions: all the authors contributed to the conception and design the study. LVFO and NSFJ provided the idea for the study, established the hypothesis and wrote the original proposal. NSFJ conducted the data collection. AMB, SRS and FSSLF carried out pulmonary function tests. NSFJ, FSSLF and LVFO analyzed the data. This research paper was written by NSFJ, FSSLF and LVFO, with input from all co-authors. All authors significantly contributed to this study and read and approved the final manuscript
\end{abstract}


ambulatory between 2004 and 2012. Results: The sample consisted of 232 patients (134 females; mean age: 52.9 years \pm 17.7 ; body mass index: $23.5 \mathrm{~kg} / \mathrm{m}^{2} \pm 4.4$ ). The predominant symptoms were cough (91.4\%), expectoration (85.8\%) and dyspnea (76.3\%). The majority of cases were of a non-tuberculosis etiology (64.7\%). Regarding lung function, the obstructive breathing pattern was predominant (43.5\%). The most common comorbidities were of a cardiovascular origin (51.0\%). Conclusions: Adult patients with non-cystic fibrosis bronchiectasis (mainly post-infection or post-tuberculosis in origin) are characterized by a low educational level, excessive cough, sputum, dyspnea, muscle fatigue, an obstructive breathing pattern with frequent hypoxemia and multiple comorbidities, mainly of a cardiovascular origin. However, our patients have a low index of exacerbations and hospitalizations that can be assigned to a clinical protocol for monitoring.

Keywords: Bronchiectasis. Cough. Lung injury. Respiratory function test. Quality of life.

\section{Resumo}

Introdução: Bronquiectasia é uma doença crônica caracterizada pela dilatação permanente dos brônquios e bronquíolos acompanhada por alterações inflamatórias nas paredes dessas estruturas e parênquima pulmonar adjacente. Objetivo: $O$ objetivo do presente estudo é realizar uma caracterização clínica e funcional de pacientes adultos com bronquiectasias e fibrose não cística. Métodos: Um estudo clínico descritivo e retrospectivo foi realizado com pacientes com bronquiectasias e fibrose não cística atendidos em um ambulatório de pulmão entre 2004 e 2012. Resultados: A amostra foi composta por 232 pacientes (134 mulheres, idade média: 52,9 anos $\pm 17,7$, índice de massa corporal: $\left.23,5 \pm 4,4 \mathrm{~kg} / \mathrm{m}^{2}\right)$. Os sintomas predominantes foram tosse (91,4\%), expectoração (85,8\%) e dispneia (76,3\%). A maioria dos casos foi de etiologia não tuberculosa (64,7\%). Em relação à função pulmonar, o padrão de respiração obstrutiva foi predominante (43,5\%). As comorbidades mais comuns foram de origem cardiovascular (51,0\%). Conclusões: pacientes adultos com bronquiectasias de fibrose não cística (principalmente pós-infecção ou pós-tuberculose de origem) são caracterizados por um baixo nível de escolaridade, tosse excessiva, expectoração, dispneia, fadiga muscular, um padrão de respiração obstrutiva com hipoxemia frequente e múltiplas comorbidades, essencialmente de origem cardiovascular. No entanto, nossos pacientes têm um baixo índice de exacerbações e hospitalizações que podem ser atribuídos a um protocolo clínico para o acompanhamento.

Palavras-chave: Bronquiectasia. Tosse. Lesão pulmonar. Teste de função respiratória. Qualidade de vida.

\section{Introduction ${ }^{2}$}

Bronchiectasis is a chronic disorder characterized by permanent dilation of the bronchi and bronchioles accompanied by inflammatory changes in the walls of these structures and adjacent lung parenchyma due to repeated infection and inflammatory insults, leading to impaired mucociliary clearance and the excessive production of sputum (1-3). This condition is more frequent in females and generally occurs in the sixth decade of life (4). The most common clinical manifestations are chronic cough, fever, excessive purulent expectoration, sinusitis and muscle fatigue $(4,5)$.

The prevalence of bronchiectasis is not well defined and likely varies significantly between populations (6). It is estimated that at least 110,000 adult patients in the United States of America (USA) are diagnosed with bronchiectasis, with prevalence rates of 4.2/100,000 individuals between 18 and 34 years of age and 272/100,000 individuals aged 75 years or older (7). Particular demographic groups are at greater risk for bronchiectasis, such as those with little access to health care and high rates of lung

\footnotetext{
2 Abbreviations: HRCT, high-resolution computed tomography; mmol/L, micromoles per liters; BMI, body mass index; IgE, imunoglobulin; g/m2, grams per square meter; ml, milliliter; mm, millimeter; FVC, Forced vital capacity; FEV1, forced expiratory volume in the first second; SD, standard deviation; PaO2, parcial pressure of oxygen; SaO2, oxygen saturation; PaCO2, parcial pressure of carbon dioxide; Sp02, periferic saturation of oxygen.
} 
infection in childhood (2). In a study carried out at a Brazilian hospital specialized in lung diseases, $0.4 \%$ $(\mathrm{n}=170)$ of the total number of hospitalizations $(\mathrm{n}=42,500)$ between 1978 and 2001 were diagnosed as bronchiectasis (8).

High-resolution computed tomography (HRCT) of the thorax (9-11), which is currently the gold standard for the diagnosis of this condition, has demonstrated that bronchiectasis is a major respiratory disease $(4,6)$. Despite the increasingly frequent diagnosis of bronchiectasis not associated with cystic fibrosis, especially in developing countries, the general and functional characteristics of patients have been under-investigated.

The aim of the present study was to describe the clinical and lung function profile of adult patients with non-cystic fibrosis bronchiectasis, offering a comparison of tuberculosis and non-tuberculosis etiologies.

\section{Methods}

Subjects and study design

A clinical, descriptive, retrospective, case-series study was carried out. Medical files from 232 patients referred to a lung clinic in Brazil between 2004 and 2012 were reviewed. The inclusion criteria were a clinical history compatible with bronchiectasis (dry or productive cough and/or report of recurring respiratory infection) and thorax HRCT compatible with bronchiectasis. The exclusion criteria were bronchiectasis stemming from cystic fibrosis (chloride level in sweat $>60 \mathrm{mmol} / \mathrm{L}$ ).

\section{Ethical considerations}

The study will be conducted based on the ethical standards established in the 1961 Declaration of Helsinki (as revised in Hong Kong in 1989 and Edimburgh, Scotland in 2000), and is in compliance with the Regulatory Guidelines and Norms for Research Involving Human Subjects of the National Health Board of the Brazilian Health Ministry issued in October 1996, and was approved by the Human Research Ethics Committee of the Universidade Nove de Julho, Brazil (protocol n. 329759/2010). All participants signed a statement of informed consent and will be allowed to abandon the study at any time with no negative consequences. All procedures of the study was confidential.
Clinical assessment

Patient histories with a suspicion of bronchiectasis were collected by a pulmologist, who also performed the physical exams. The following aspects were investigated: patient's report of main respiratory complaints; the presence of cyanosis and comorbidities; pulmonary auscultation; weight, height and body mass index (BMI); current and/or past smoking habits (expressed in pack years); schooling; medications in use, lung function and blood gas analysis.

For the investigation of the etiology of bronchiectasis, the patients were routinely submitted to the following exams: microbiological exam of sputum (cultures for acid/alcohol-resistant bacilli), immunoglobin levels (including IgE), chloride level in sweat and sperm analysis in cases of male patients with report or suspicion of associated infertility.

The method used for determining chloride in the sweat was pilocarpine iontophoresis, which is considered the best method of sweat stimulation (12, 13). Sweat was collected for 30 minutes onto preweighed gauze or filter paper low in sodium chloride. A minimum sweat rate of $1 \mathrm{~g} / \mathrm{m}^{2}$ body surface area/min was required. A volume of 50 to $100 \mathrm{ml}$ was considered adequate. A sweat chloride level above $60 \mathrm{mmol} / \mathrm{l}$ on two different tests was used to rule out cystic fibrosis (13).

\section{HRCT of the thorax}

All patients underwent HRCT of the chest (HiSpeed Advantage; General Electric Medical Systems, Milwaukee, WI, USA). High-resolution images were obtained in full inspiration for all patients, while expiratory images were acquired from patients suspected of having small airway disease. High-resolution images were obtained at 1-mm collimation at $1-\mathrm{mm}$ intervals from the lung apices to the bases. Images were reconstructed with an algorithm using standard window setting (window level: $700 \mathrm{HU}$; window width: $1500 \mathrm{HU}$ ). The presence of bronchiectasis was based on 1) lack of tapering of the bronchi, 2) bronchial dilatation (when the internal diameter was at least 110\% larger than the adjacent pulmonary artery) or 3 ) visualization of the peripheral bronchi within $1 \mathrm{~cm}$ of the costal pleural surface or adjacent mediastinal pleural surface (14). Cylindrical 
bronchiectasis was diagnosed based on dilatation and thickening of the bronchial wall (bronchial wall: arterial wall ratio $>1$ ) (15) and cystic bronchiectasis was diagnosed by the presence of thinwalled cystic spaces that may contain fluid seen in subsequent axial cuts either agglomerated or in a branching pattern (16).

Pulmonary function testing and blood gas analysis

All patients underwent forced spirometry following the guidelines of the American Thoracic Society/ European Respiratory Society (17). Forced vital capacity (FVC), forced expiratory volume in the first second (FEV1) and FEV1/FVC ratio were measured prior to and 15-20 minutes after the use of a shortacting bronchodilator (albuterol $400 \mathrm{mcg}$ ) (18). All tests were performed during clinical stability (no occurrence of increased dyspnea, increased sputum and/or change in sputum purulence or change in medication use), with the discontinuation of shortacting and long-acting $\beta 2$-agonists six and 12 hours prior to the test, respectively. When a patient had more than one spirometric reading in the previous three months, the most recent was considered for analysis.

The lung function tests were carried out using an Elite spirometer (Med Graphics Corporation; St Paul, MN, USA). Arterial blood samples were collected in heparinized blood-gas syringes and analyzed using a benchtop blood-gas analyzer (pHOx Stat Profile Plus L, Nova Biomedical, Waltham MA, USA).

\section{Statistical analysis}

Descriptive and numerical data were reported as mean \pm standard deviation (SD) or mean with $\pm 95 \%$ confidence interval. Comparisons between groups (tuberculosis versus non-tuberculosis etiology) were performed using the Student's $t$-test or Mann-Whitney U test, depending on the type of data distribution. Pearson's chi-squared test was used to compare proportions (categorical data) between the two groups. The level of statistical significance was set at $5 \%(\mathrm{p}<0.05)$ for all tests. The SPSS Version 16.0 statistical software was used for the data analysis (IBM, Chicago, IL, USA).

\section{Results}

Table 1 displays the demographic data on the entire sample $(n=232)$. Mean age was 52.9 years \pm 17.7 . The female gender was predominant (57.8\%). Mean BMI was $23.5 \mathrm{Kg} / \mathrm{m}^{2} \pm 4.4 ; 22.9 \%$ of the patients had a BMI $<20.0 \mathrm{~kg} / \mathrm{m}^{2}, 40.9 \%$ had a BMI between 20.0 and $25.0 \mathrm{~kg} / \mathrm{m}^{2}$ and $36.2 \%$ had a BMI $\geq 25.0 \mathrm{~kg} / \mathrm{m}^{2}$. Eighty-two patients (36.2\%) were ex-smokers (volume ranging from 2.5 to 100 pack years). Only four patients were current smokers. A total of $64.6 \%$ of the sample had a low level of schooling (incomplete elementary education).

The majority of cases of non-cystic fibrosis bronchiectasis were of a non-tuberculosis etiology (64.7\%), most often attributed to post-infection causes (39.6\%) and idiopathic causes (18.5\%) (Table 2). The predominant symptoms were cough (91.4\%), expectoration (85.8\%) and dyspnea (76.3\%). No significant differences were found between groups (tuberculosis versus non-tuberculosis etiology) regarding the distribution of symptoms (Table 3). The most frequent sign was crackling sound (137 cases; 59\%).

Regarding lung function, the obstructive breathing pattern was predominant (43.5\%), followed by the restrictive (15.9\%) and mixed (9.9\%) patterns. Table 4 displays the distribution of the spirometric findings based on the guidelines of the American Thoracic Society/European Respiratory Society) (17) among patients with tuberculosis and non-tuberculosis etiologies. No statistically significant differences were found between groups ( $p=0.63$ ). Moreover, thirty patients had normal spirometric readings.

Table 5 displays the spirometric and blood gas analysis findings according to infectious and noninfectious etiologies. Once again, no statistically significant differences were found between groups. The blood gas analysis revealed the presence of gasexchange abnormalities in some patients: 65 patients (32.8\%) exhibited hypoxemia, among which 13 cases $(5.6 \%)$ had parcial pressure of oxygen $\left(\mathrm{PaO}_{2}\right) \leq$ $55 \mathrm{mmHg}, 10$ cases (4.3\%) had oxygen saturation $\left(\mathrm{SaO}_{2}\right) \leq 88 \%$ and 15 cases $(6.5 \%)$ exhibited hypercapnia (parcial pressure of carbon dioxide $-\mathrm{PaCO}_{2} \geq$ $45 \mathrm{mmHg}$ ). Fifteen patients (6.5\%) were under prolonged home-based oxygen therapy (11 cases in the group with a non-tuberculosis etiology).

The most common comorbidities were of a cardiovascular origin (51.0\%), especially systemic arterial hypertension. One hundred seventy-five of the patients 
Table 1- Demographic and anthropometric characteristics of sample

\begin{tabular}{|c|c|}
\hline Characteristics & $\mathrm{n}=232$ \\
\hline Age (years) & $52.9 \pm 17.7$ \\
\hline \multicolumn{2}{|l|}{ Sex } \\
\hline Male & $98(42.2 \%)$ \\
\hline Female & $134(57.8 \%)$ \\
\hline Weight (Kg) & $60.9 \pm 12.6$ \\
\hline Body mass index (Kg/m²) & $23.5 \pm 4.4$ \\
\hline Smokers (current and ex-smokers) & $82(36.2 \%)$ \\
\hline Pack years & $21.7 \pm 15.3$ \\
\hline \multicolumn{2}{|l|}{ Education } \\
\hline - Low & $64.6 \%$ \\
\hline - Medium & $5.6 \%$ \\
\hline - High & $29.8 \%$ \\
\hline Characteristics & $\mathrm{n}=232$ \\
\hline Age (years) & $52.9 \pm 17.7$ \\
\hline \multicolumn{2}{|l|}{ Sex } \\
\hline Male & 98 (42.2\%) \\
\hline Female & $134(57.8 \%)$ \\
\hline Weight (Kg) & $60.9 \pm 12.6$ \\
\hline Body mass index (Kg/m2) & $23.5 \pm 4.4$ \\
\hline Smokers (current and ex-smokers) & $82(36.2 \%)$ \\
\hline Pack years & $21.7 \pm 15.3$ \\
\hline \multicolumn{2}{|l|}{ Education } \\
\hline - Low & $64.6 \%$ \\
\hline - Medium & $5.6 \%$ \\
\hline - High & $29.8 \%$ \\
\hline Characteristics & $n=232$ \\
\hline Age (years) & $52.9 \pm 17.7$ \\
\hline \multicolumn{2}{|l|}{ Sex } \\
\hline Male & $98(42.2 \%)$ \\
\hline Female & $134(57.8 \%)$ \\
\hline Weight (Kg) & $60.9 \pm 12.6$ \\
\hline Body mass index (Kg/m2) & $23.5 \pm 4.4$ \\
\hline Smokers (current and ex-smokers) & $82(36.2 \%)$ \\
\hline Pack years & $21.7 \pm 15.3$ \\
\hline \multicolumn{2}{|l|}{ Education } \\
\hline - Low & $64.6 \%$ \\
\hline - Medium & $5.6 \%$ \\
\hline - High & $29.8 \%$ \\
\hline Characteristics & $n=232$ \\
\hline Age (years) & $52.9 \pm 17.7$ \\
\hline \multicolumn{2}{|l|}{ Sex } \\
\hline Male & $98(42.2 \%)$ \\
\hline Female & $134(57.8 \%)$ \\
\hline Weight (Kg) & $60.9 \pm 12.6$ \\
\hline
\end{tabular}


Table 1- Demographic and anthropometric characteristics of sample

\begin{tabular}{lc}
\hline Characteristics & $\mathbf{n}=\mathbf{2 3 2}$ \\
\hline Body mass index $\left(\mathrm{Kg} / \mathrm{m}^{2}\right)$ & $23.5 \pm 4.4$ \\
Smokers (current and ex-smokers) & $82(36.2 \%)$ \\
Pack years & $21.7 \pm 15.3$ \\
Education & \\
- Low & $64.6 \%$ \\
- Medium & $5.6 \%$ \\
- High & $29.8 \%$ \\
\hline
\end{tabular}

Legend: $\mathrm{Kg}=$ kilogram; $\mathrm{m}^{2}=$ square meters.

Source: Research data.

Note: Data expressed as mean \pm SD for parametric data and as percentages for categorical data.

Table 2 - Causes of non-cystic fibrosis bronchiectasis $(n=232)$

\begin{tabular}{|c|c|}
\hline Causes of non-cystic fibrosis bronchiectasis & $\mathrm{n}=232$ \\
\hline $\begin{array}{l}\text { Post-infection }{ }^{1} \\
\text { Sequelae from pulmonary tuberculosis }\end{array}$ & $\begin{array}{l}92(39.6 \%) \\
82(35.3 \%)\end{array}$ \\
\hline Idiopathic ${ }^{2}$ & $43(18.5 \%)$ \\
\hline Kartagener's syndrome ${ }^{3}$ & $6(2.6 \%)$ \\
\hline Rheumatoid arthritis & $4(1.8 \%)$ \\
\hline Primary ciliary dyskinesia ${ }^{4}$ & $1(0.4 \%)$ \\
\hline Toxic inhalation & $1(0.4 \%)$ \\
\hline Ulcerative colitis & $1(0.4 \%)$ \\
\hline Immune deficiencies & $1(0.4 \%)$ \\
\hline Mounier-Kühn syndrome ${ }^{5}$ & $1(0.4 \%)$ \\
\hline Causes of non-cystic fibrosis bronchiectasis & $n=232$ \\
\hline $\begin{array}{l}\text { Post-infection }{ }^{1} \\
\text { Sequelae from pulmonary tuberculosis }\end{array}$ & $\begin{array}{l}92(39.6 \%) \\
82(35.3 \%)\end{array}$ \\
\hline Idiopathic² & $43(18.5 \%)$ \\
\hline Kartagener's syndrome ${ }^{3}$ & $6(2.6 \%)$ \\
\hline Rheumatoid arthritis & $4(1.8 \%)$ \\
\hline Primary ciliary dyskinesia ${ }^{4}$ & $1(0.4 \%)$ \\
\hline Toxic inhalation & $1(0.4 \%)$ \\
\hline Ulcerative colitis & $1(0.4 \%)$ \\
\hline Immune deficiencies & $1(0.4 \%)$ \\
\hline Mounier-Kühn syndrome ${ }^{5}$ & $1(0.4 \%)$ \\
\hline
\end{tabular}

Source: Research data.

Notes: 'Bronchiectasis with diagnosis established following episodes of pneumonia and after childhood diseases, such as measles, chicken pox, etc.

${ }^{2}$ When etiology could not be determined following extensive clinical investigation.

${ }^{3}$ Form of primary ciliary dyskinesia characterized by chronic pansinusitis, bronchiectasis and situs inversus with dextrocardia.

${ }^{4}$ Diagnosis performed on male patient with infertility and compatible alterations in semen analysis.

${ }^{5}$ Rare clinical condition characterized by abnormal dilation of trachea and main bronchi; diagnosis established through measure of tracheal diameter on thorax HRCT. 
Table 3 - Symptoms observed in patients with non-cystic fibrosis bronchiectasis according to etiology (tuberculosis versus non-tuberculosis)

\begin{tabular}{lccc}
\hline Variable & Tuberculosis etiology $(\mathbf{n}=\mathbf{8 2})$ & Non-tuberculosis etiology $(\mathbf{n}=\mathbf{1 5 0})$ & $\mathbf{p}^{*}$ \\
\hline Cough & $72(87.8 \%)$ & $140(93.3 \%)$ & 0.22 \\
Expectoration & $67(81.7 \%)$ & $131(87.3 \%)$ & 0.25 \\
Dyspnea & $66(80.5 \%)$ & $111(74.0 \%)$ & 0.33 \\
Wheezing & $54(65.9 \%)$ & $106(70.7 \%)$ & 0.46 \\
Hemoptoic/Hemoptysis & $39(47.6 \%)$ & $61(40.7 \%)$ & 0.33 \\
\hline
\end{tabular}

Legend: * chi-squared test.

Source: Research data.

Notes: Data expressed in absolute numbers and percentages.

Table 4 - Distribution of spirometric pattern in patients with non-cystic fibrosis bronchiectasis according to etiology (tuberculosis versus non-tuberculosis)

\begin{tabular}{|c|c|c|c|}
\hline & & \multicolumn{2}{|c|}{ Etiology } \\
\hline & & Tuberculosis $(n=63)$ & Non-tuberculosis $(\mathrm{n}=128)$ \\
\hline \multirow{4}{*}{ Result } & Normal & $7(11.1 \%)$ & $23(17.9 \%)$ \\
\hline & Obstructive & $34(53.9 \%)$ & 67 (52.3\%) \\
\hline & Restrictive & $14(22.2 \%)$ & $23(17.9 \%)$ \\
\hline & Mixed & $8(12.7 \%)$ & $15(11.7 \%)$ \\
\hline
\end{tabular}

Legend: $p=0.63$ (chi-squared test).

Source: Research data.

Note: Data expressed as absolute numbers and percentages.

Table 5 - Forced spirometry and blood gases analysis in patients with non-cystic fibrosis bronchiectasis according to etiology (tuberculosis versus non-tuberculosis)

\begin{tabular}{|c|c|c|c|}
\hline Variables* & Tuberculosis etiology $(n=82)$ & Non-tuberculosis etiology $(n=150)$ & $\mathrm{p} \dagger$ \\
\hline \multicolumn{4}{|c|}{ Forces spirometry** } \\
\hline FVC (L) & $2.24 \pm 0.90$ & $2.41 \pm 0.93$ & 0.21 \\
\hline FVC (\% pred.) & $66.7 \pm 23.7$ & $68.6 \pm 19.2$ & 0.56 \\
\hline $\mathrm{FEV}_{1}(\mathrm{~L})$ & $1.45 \pm 0.75$ & $1.58 \pm 0.82$ & 0.26 \\
\hline $\mathrm{FEV}_{1}(\%$ pred.) & $53.0 \pm 25.1$ & $55.6 \pm 23.1$ & 0.47 \\
\hline $\mathrm{FEV}_{1} / \mathrm{FVC}(\%)$ & $62.4 \pm 16.5$ & $64.7 \pm 14.6$ & 0.31 \\
\hline Post-FVC (L) & $2.37 \pm 0.86$ & $2.52 \pm 0.97$ & 0.35 \\
\hline Post-FVC (\% pred.) & $69.1 \pm 22.6$ & $71.2 \pm 18.8$ & 0.52 \\
\hline Post-FEV $_{1}(\mathrm{~L})$ & $1.48 \pm 0.75$ & $1.70 \pm 0.86$ & 0.11 \\
\hline Post-FEV 1 (\% pred.) & $55.5 \pm 26.5$ & $58.1 \pm 22.5$ & 0.49 \\
\hline Post - FEV $/$ FVC (\%) & $63.4 \pm 15.9$ & $65.5 \pm 14.8$ & 0.37 \\
\hline \multicolumn{4}{|c|}{ Arterial gas analysis } \\
\hline $\mathrm{pH}$ & $7.41 \pm 0.03$ & $7.41 \pm 0.03$ & 0.96 \\
\hline $\mathrm{PaO}^{2}(\mathrm{mmHg})$ & $72.2 \pm 11.9$ & $70.7 \pm 13.7$ & 0.56 \\
\hline
\end{tabular}


Table 5 - Forced spirometry and blood gases analysis in patients with non-cystic fibrosis bronchiectasis according to etiology (tuberculosis versus non-tuberculosis)

conclusion

\begin{tabular}{llll}
\hline Variables* & Tuberculosis etiology $(\mathbf{n}=\mathbf{8 2})$ & Non-tuberculosis etiology $(\mathbf{n}=\mathbf{1 5 0})$ & $\mathbf{p} \dagger$ \\
\hline $\mathrm{PaCO}^{2}(\mathrm{mmHg})$ & $40.6 \pm 5.26$ & $39.9 \pm 5.70$ & 0.53 \\
$\mathrm{HCO}^{3}(\mathrm{mEq} / \mathrm{L})$ & $25.4 \pm 3.85$ & $25.0 \pm 3.85$ & 0.57 \\
$\mathrm{SaO}^{2}(\%)$ & $93.5 \pm 3.7$ & $93.5 \pm 3.58$ & 0.98 \\
\hline
\end{tabular}

Legend: ${ }^{*}=$ Values presented as means $\pm \mathrm{SD} ;{ }^{* \star}=$ Data available for 191 patients; $\dagger=$ Student's t-test for two independent samples (tuberculosis versus non-tuberculosis etiology); $\mathrm{FVC}=$ forced vital capacity; FEV ${ }^{1}=$ forced expiratory volume in one second; $\mathrm{SaO}{ }^{2}=\mathrm{arterial}$ saturation of oxygen; $\mathrm{PaO}^{2}=$ arterial oxygen pressure; $\mathrm{PaCO}^{2}=$ carbon dioxide pressure; $\mathrm{HCO}^{3}=$ sodium bicarbonate; $\%$ pred. $=\%$ of predicted values.

Source: Research data.

(75.4\%) made regular use of respiratory medications; 69 (29.7\%) used long-lasting $\beta_{2}$ agonists, 45 (19.4\%) used short-lasting $\beta_{2}$ agonists/ipratropium, 39 (16.8\%) used inhaled corticosteroids and 22 (9.5\%) used shortlasting $\beta_{2}$ agonists/inhaled corticoid steroids. One hundred eight patients (46.5\%) made use of non-respiratory medications, among which anti-hypertension drugs and diuretics figured prominently.

\section{Discussion}

In the present study, non-cystic fibrosis bronchiectasis was found predominantly in the female gender (57.8\%) and was more common among individuals with a low level of schooling, which is a characteristic of developing countries, as described by King et al. (4) and Nicotra et al. (19). The mean BMI $\left(23.5 \pm 4.4 \mathrm{~kg} / \mathrm{m}^{2}\right)$ demonstrates that the patients were within the ideal weight range (20). Most subjects had never smoked (63.8\%), which is similar to the findings described in the study by King et al. (21) and indicates little likelihood of an association with tobacco-related diseases.

The main cause of non-cystic fibrosis bronchiectasis in our patients was infection, followed by sequelae from pulmonary tuberculosis, which are also characteristics of developing countries (22-24). Together, these conditions accounted for $74.9 \%$ of the causes. Pasteur et al. (25) found the main causes to be idiopathic in origin (53\%) and post-infection (29\%), whereas these figures were respectively $18.5 \%$ and $39.6 \%$ in the present study. These differences may be explained by the fact that pulmonary tuberculosis is not common in developed countries.
The main symptoms were cough and sputum, which is in agreement with findings described in the international scientific literature $(4,5,26)$. Moreover, dyspnea (shortness of breath), fatigue and hemoptysis were found in a large portion of the patients $(76.3 \%$, $69.4 \%$ and $43.1 \%$, respectively) $(21,26,27)$. However, no differences were found between the two groups (tuberculosis and non-tuberculosis etiology) regarding symptoms. The most common noise encountered during pulmonary auscultation was crackling, which is also in agreement with findings described in the international scientific literature $(2,21)$.

Although related to bronchial dilation, non-cystic fibrosis bronchiectasis more often results in air flow obstruction, which partially explains the findings of inflamed bronchioles and sputum in the airways, regardless of the tuberculosis or non-tuberculosis etiology (28). In the present study, airway obstruction was predominantly moderate ( $40 \%$ to $60 \%$ of predicted $\mathrm{FEV}_{1}$ ) (29), which confirms findings described by King et al. (4) Mean $\mathrm{SpO}_{2}$ was $94 \% \pm 3.8$, which is within the range of normality. However, $32.8 \%$ of subjects were hypoxemic (30) and 5.6\% had severe hypoxemia. Fifteen patients required home oxygen supplementation, among whom only four had a tuberculosis etiology, which apparently had no influence on this dependence.

Long-acting $\beta_{2}$-agonists with inhaled corticosteroids were the most employed respiratory medications. Although there is no clear evidence regarding this form of treatment (31), many patients reported an improvement in symptoms. Anti-hypertensive agents and diuretics were the most employed nonrespiratory medications, which indirectly confirms systemic arterial hypertension as the most common comorbidity in the present study. In agreement 
with previous studies (32), $10 \%$ of the subjects were regularly using macrolides due to their antiinflammatory properties.

\section{Limitations of the study}

Although unlikely, there may be cases of cystic fibrosis with a normal chloride level in the sweat and associated with bronchiectasis.

\section{Conclusions}

Based on the results of the present study carried out at in a real practice with non-cystic fibrosis bronchiectasis, the clinical profile of patients with bronchiectasis (mainly post-infection or post-tuberculosis in origin) is characterized by a low educational level, excessive cough, sputum, dyspnea, muscle fatigue, an obstructive spirometric pattern with a frequent hypoxemia and multiple comorbidities, mainly of a cardiovascular origin. However, our patients have a low index of exacerbations and hospitalizations that can be assigned to a clinical protocol for monitoring. All patients in the present study made regular use ( 3 times a week) of azithromycin (250 mg), according to the clinical protocol.

\section{Acknowledgments}

LVFO received a grant from $\mathrm{CNPq}$ (Research Productivity modality - PQID, process number 307618/2010-2).

\section{References}

1. Lambrecht BN, Neyt K, Geurts van Kessel CH. Pulmonary defence machanisms and inflammatory pathways in bronchiectasis. Eur Respir Mon. 2011;52(2):11-21.

2. Barker AF. Bronchiectasis. N Engl J Med. 2002;346 (18):1383-93.

3. O'Donnell AE. Bronchiectasis. Chest. 2008;134 (4):815-23.

4. King P, Holdsworth S, Freezer N, Holmes P. Bronchiectasis. Intern Med J. 2006;36(11):729-37.
5. Cohen M, Sahn SA. Bronchiectasis in Systemic Diseases. Chest. 1999;116(4):1063-74.

6. King P. Pathogenesis of bronchiectasis. Paediatr Respir Rev. 2011;12(2):104-10.

7. Weycker D, Edelsberg J, Oster G, Tino G. Prevalence and economic burden of bronchiectasis. Clin Pulm Med. 2005;12(4):205-9.

8. Moreira JS, Porto NS, Camargo JJP, Felicetti JC, Cardoso PFG, Moreira ANS, et al. Bronchiectasis: diagnostic and therapeutic features: a study of 170 patients. J Pneumol. 2003;29(5):258-63.

9. Naidich DP, McCauley DI, Khouri NF, Stitik FP, Siegelman SS. Computed tomography of bronchiectasis. J Comput Assist Tomogr. 1982;6(3):437-44.

10. Grenier P, Maurice F, Musset D, Menu Y, Nahum H. Bronchiectasis: assessment by thin-section CT. Radiology. 1986;161(1):95-9.

11. Cooke JC, Cume DC, Morgan AD, Kerr IH, Delany D, Strickland B, et al. Role of computed tomography in diagnosis of bronchiectasis. Thorax. 1987;42(4):272-7.

12. Association of Clinical Biochemistry. Guidelines for the performance of the sweat test for the investigation of cystic fibrosis in the UK. Report from the Multidisciplinary Working Group, 2003 [cited 2013 Dec 5]. Available at: http://www.acb.org.uk/docs/defaultsource/guidelines/Sweat.pdf?sfvrsn=0

13. De Boeck K, Wilschanski M, Castellani C, Taylor C, Cuppens H, Dodge J, et al. Diagnostic Working Group. Cystic fibrosis: terminology and diagnostic algorithms. Thorax. 2006 Jul;61(7):627-35.

14. Smith IE, Jurriaans E, Diederich S, Ali N, Shneerson JM, Flower CD. Chronic sputum production: correlations between clinical features and findings on high resolution computed tomographic scanning of the chest. Thorax. 1996;51(9):914-8.

15. Kim JS, Müller NL, Park CS, Grenier P, Herold CJ. Cylindrical bronchiectasis: diagnostic findings on thinsection CT. AJR Am J Roentgenol. 1997;168(3):751-4.

16. Marti-Bonmati L, Catala FJ, Ruiz Perales F. Computed tomography differentiation between cystic bronchiectasis and bullae. J Thorac Imaging. 1991;7(1):83-5.

17. Miller MR, Hankinson J, Brusasco V, Burgos F, Casaburi R, Coates A, et al. Standardisation of spirometry. Eur Respir J. 2005 Aug;26(2):319-38. 
18. Pereira CAC, Jansen JM, Barreto SSM, Marinho J, Sulmonett N, Dias RM. Espirometria. In: Diretrizes para testes de função pulmonar. J Pneumol. 2002;28(Supl. 3): S1-S82.

19. Nicotra MB, Rivera M, Dale AM, Shepherd R, Carter R. Clinical, pathophysiologic, and microbiologic characterization of bronchiectasis in an aging cohort. Chest. 1995;108(4):955-61.

20. World Health Organization - WHO. Obesity : preventing and managing the global epidemic. Report of a WHO Consultation. WHO Technical Report Series 894. Geneva: World Health Organization; 2000.

21. King PT, Holdsworth SR, Freezer NJ, Villanueva E, Holmes PW. Characterisation of the onset and presenting clinical features of adult bronchiectasis. Respir Med. 2006;100(12):2183-9.

22. Sancho LMM, Paschoalini MS, Vicentini FC, Fonseca MH, Jatene FB. Estudo descritivo do tratamento cirúrgico das bronquiectasias. J Pneumol. 1996;22(5):241-6.

23. Ashour M, Al-Kattan KM, Jain SK, Al Majed S, Al Kassimi F, Mobaireek A, et al. Surgery for unilateral bronchiectasis: results and prognostic factors. Tubercle Lung Dis. 1996;77(2):168-72.

24. Bogossian M, Santoro IL, Jamnik S, Romaldini H. Bronquiectasias: estudo de 314 casos de tuberculose x nãotuberculose. J Pneumol. 1998;24(1):11-6.

25. Pasteur MC, Helliwell SNM, Houghton SJ, Webb SC, Foweraker JE, Coulden RA. An investigation into causative factors in patients with bronchiectasis. Am J Respir Crit Care Med. 2000;162(4):1277-84.

26. Habesoglu MA, Ugurlu AO, Eyuboglu FO. Clinical, radiologic, and functional evaluation of 304 patients with bronchiectasis. Ann Thorac Med. 2011;6(3):131-6.

27. King PT, Holdsworth SR, Freezer NJ, Villanueva E, Gallagher M, Homes PW. Outcome in adult bronchiectasis. COPD. 2005;2(1):27-34.

28. Roberts HR,Wells AU, Milne DG, Rubens MB, Kolbe J, Cole PJ, et al. Airflow obstruction in bronchiectasis: correlation between computed tomography features and pulmonary function tests. Thorax 2000;55(3):198-204.

29. Pereira, CAC. I Consenso Brasileiro sobre Espirometria. J Pneumol. 1996;22(3)105-164.
30. Sorbini CA, Grassi V, Solinas E, Muiesan G. Arterial oxygen tension in relation to age in healthy subjects. Respiration. 1968;25(1):3-13.

31. Pizzutto SJ, Upham JW, Yerkovich ST, Chang AB. Inhaled non-steroid anti-inflammatories for children and adults with bronchiectasis. Cochrane Database Syst Rev. 2010 Apr 14;(4):CD007525.

32. King PT, Holmes PW. Use of antibiotics in bronchiectasis. Reviews on Recent Clinical Trials. 2012;7(1):24-30.

Received: 01/16/2013

Recebido: 16/01/2013

Approved: 09/17/2013

Aprovado: 17/09/2013 